\title{
CLASSES OF ANALYTIC FUNCTIONS RELATED TO A COMBINATION OF TWO CONVEX FUNCTIONS
}

\author{
J. DZIOK AND K. I. NOOR
}

Abstract. In the paper we introduce classes of functions related to a class of linear combinations of two convex functions. By using properties of multivalent prestarlike functions we obtain various inclusion relationships between defined classes of functions. Some applications of the main results are also considered.

Mathematics subject classification (2010): 30C45, 30C50, 30C55.

Keywords and phrases: Analytic functions, bounded variation, convex function, prestarlike function, linear operator, Hadamard product, subordination.

\section{REFERENCES}

[1] R. Aghalary, S. B. Joshi, R. N. Mohapatra, V. Ravichandran, Subordinations for analytic functions defined by the Dziok-Srivastava linear operator, Appl. Math. Comput. 187 (2007), 13-19.

[2] R. M. Ali, M. N. Mahnaz, V. Ravichandran, K. G. Subramanian, Convolution properties of classes of analytic and meromorphic functions, J. Inequal. Appl. (2010), 2010:385728.

[3] N. E. Cho, O. S. KWON, H. M. SRIVAstava, Inclusion relationships and argument properties for certain subclasses of multivalent functions associated with a family of linear operators, J. Math. Anal. Appl. 292 (2004), 470-483.

[4] H. B. CoOnce, M. R. ZIEgler, Functions with bounded Mocanu variation, Rev. Roumaine Math. Pures Appl. 19 (1974), 1093-1104.

[5] J. DZIOK, Applications of multivalent prestarlike functions, Appl. Math. Comput. 221 (2013), 230238.

[6] J. DzIOK, Generalizations of strongly starlike functions, Taiwanese J. Math. 18 (2014), 39-51.

[7] J. DZIOK, Classes of functions associated with the bounded Mocanu variation, J. Inequal. Appl. (2013), 2013:349.

[8] J. DZIOK, H. M. SRIVASTAVA, Classes of analytic functions associated with the generalized hypergeometric function, Appl. Math. Comput. 103 (1999), 1-13.

[9] P. J. Eenigenburg, S. S. Miller, P. T. Mocanu, O. M. Reade, Second order differential inequalities in the complex plane, J. Math. Anal. Appl. 65 (1978), 289-305.

[10] J.-L. LIU, K. I. NoOR, On subordinations for certain analytic functions associated with Noor integral operator, Appl. Math. Comput. 187 (2007), 1453-1460.

[11] M.-S. LiU, Y.-C. ZHU, H. M. SRivastava, Properties and characteristics of certain subclasses of starlike functions of order $\beta$, Math. Comput. Modelling, 48 (2008), 402-419.

[12] A. LYZZAIK, Multivalent functions of bounded boundary rotation and weakly close-to-convex functions, Proc. London Math. Soc. 51 (1985), no. 3, 478-500.

[13] S. S. Miller, P. T. Mocanu, Differential subordinations: theory and applications, Series on Monographs and Textbooks in Pure and Applied Mathematics, Vol. 225, Marcel Dekker, New York, 2000.

[14] K. I. Noor, On some subclasses of functions with bounded radius and bounded boundary rotation, Panamer. Math. J. 6 (1996), no. 1, 75-81.

[15] K. I. NOOR, S. HuSSAIn, On certain analytic functions associated with Ruscheweyh derivatives and bounded Mocanu variation, J. Math. Anal. Appl. 340 (2008), no. 2, 1145-1152.

[16] K. I. NoOR, S. N. MALIK, On generalized bounded Mocanu variation associated with conic domain, Math. Comput. Modelling 55 (2012), no. 3-4, 844-852. 
[17] K. I. Noor, A. Muhammad, On analytic functions with generalized bounded Mocanu variation, Appl. Math. Comput. 196 (2008), no. 2, 802-811.

[18] K. I. NoOR, W. UL-HAQ, On some implication type results involving generalized bounded Mocanu variations, Comput. Math. Appl. 63 (2012), no. 10, 1456-1461.

[19] Ö. ÖzKan, O. Altintaş, Applications of differential subordination, Appl. Math. Lett. 19 (2006), $728-734$.

[20] K. Padmanabhan, R. Parvatham, Properties of a class of functions with bounded boundary rotation, Ann. Polon. Math. 31 (1975), 311-323.

[21] K. PIEJKO, J. SoKóŁ, On the Dziok-Srivastava operator under multivalent analytic functions, Appl. Math. Comp. 177 (2006), 839-843.

[22] B. PINCHUK, Functions with bounded boundary rotation, Isr. J. Math. 10 (1971), 7-16.

[23] B. PINCHuK, The Hardy class of functions of bounded boundary rotation, Proc. Amer. Math. Soc. 38 (1973), 355-360.

[24] S. Ruscheweyh, Convolutions in geometric function theory, Sem. Math. Sup. 83, Les Presses de l'Université de Montréal, 1982.

[25] S. Ruscheweyh, Linear operators between classes of prestarlike functions, Comm. Math. Helv. 52 (1977), 497-509.

[26] J. SOKó , L. TROJNAR-SPELINA, Convolution properties for certain classes of multivalent functions, J. Math. Anal. Appl. 337 (2008), 1190-1197.

[27] S. Supramaniam, R. M. Ali, S. K. Lee, V. Ravichandran, Convolution and differential subordination for multivalent functions, Bull. Malays. Math. Sci. Soc. 32 (2009) 351-360. 